\title{
Fecal microbiota transplantation: donor relation, fresh or frozen, delivery methods, cost-effectiveness
}

\section{Daryl Ramai ${ }^{a}, K_{\text {Karl Zakhia }}{ }^{b}$, Andrew Ofosu', Emmanuel Oforic, Madhavi Reddyc}

The Brooklyn Hospital Center, Academic Affiliate of The Icahn School of Medicine at Mount Sinai, Clinical Affiliate of The Mount Sinai Hospital, Brooklyn; Elmhurst Medical Center, New York, USA

\begin{abstract}
Fecal microbiota transplantation (FMT) has evolved into a robust and efficient means for treating recurrent Clostridium difficile infection (CDI). Our narrative review looks at the donor selection, preparation, delivery techniques and cost-effectiveness of FMT. We searched electronic databases, including PubMed, MEDLINE, Google Scholar, and Cochrane Databases, for studies that compared the biological effects of donor selection, fresh or frozen fecal preparation, and various delivery techniques. We also evaluated the cost-effectiveness and manually searched references to identify additional relevant studies. Overall, there is a paucity of studies that directly compare outcomes associated with related and non-related stool donors. However, inferences from prior studies indicate that the success of FMT does not depend on the donor-patient relationship. Over time, the use of unrelated donors has increased because of the formation of stool banks and the need to save processing time and capital. However, longitudinal studies are needed to clarify the optimal freezing time before microbial function declines. Several FMT techniques have been developed, such as colonoscopy, enema, nasogastric or nasojejunal tubes, and capsules. The comparable and high efficacy of FMT capsules, combined with their convenience, safety and aesthetically tolerable mode of delivery, makes it an attractive option for many patients. Costeffective models comparing these various approaches support the use of FMT via colonoscopy as being the best strategy for the treatment of recurrent CDI.
\end{abstract}

Keywords Clostridium difficile, fecal microbiota transplantation, donor selection, capsule, colonoscopy, enema

Ann Gastroenterol 2019; 32 (1): 1-9
aDepartment of Medicine, The Brooklyn Hospital Center, Academic Affiliate of The Icahn School of Medicine at Mount Sinai, Clinical Affiliate of The Mount Sinai Hospital, Brooklyn (Daryl Ramai);

${ }^{b}$ Department of Medicine, Elmhurst Medical Center, Queens (Karl Zakhia); 'Division of Gastroenterology and Hepatology, The Brooklyn Hospital Center, Academic Affiliate of The Icahn School of Medicine at Mount Sinai, Clinical Affiliate of The Mount Sinai Hospital, Brooklyn (Andrew Ofosu, Emmanuel Ofori, Madhavi Reddy), New York, USA

\section{Conflict of Interest: None}

Funding: This work received no specific grant from any funding agency in the public, commercial, or not-for-profit sectors

Correspondence to: Daryl Ramai, MD, MScBR, Department of Medicine, The Brooklyn Hospital Center, Academic Affiliate of The Icahn School of Medicine at Mount Sinai Clinical Affiliate of The Mount Sinai Hospital, 121 Dekalb Avenue, Brooklyn, New York 11201, USA, e-mail: dramai@tbh.org

Financial Support: Supported by NIH 5 T32 DK 7356-37 (BN)

Received 5 July 2018; accepted 8 October 2018; published online 17 November 2018

DOI: https://doi.org/10.20524/aog.2018.0328

\section{Introduction}

Clostridium difficile infection (CDI) represents a major clinical and economic burden on healthcare systems [1]. The management of treatment failure and recurrent CDI poses a significant challenge, which drives the cost of healthcare because of their associated morbidity and mortality [2]. Recurrent CDI is reported in $10-30 \%$ of patients after initial treatment, with recurrence approaching $60 \%$ after the third episode of CDI [3]. Restoration of gut diversity through fecal microbiota transplantation (FMT) has emerged as an effective treatment for CDI-associated diarrhea in patients with recurrent disease after initial antibiotic therapy [4]. A variety of approaches to FMT have been studied, including outcomes associated with donor selection, fecal samples and various delivery techniques, including upper or lower gastrointestinal routes [5]. We herein review current knowledge on FMT and in particular its relationship to donor selection, use of frozen or fresh fecal samples, and delivery systems. We also review the cost-effectiveness of FMT by various delivery systems. 


\section{Materials and methods}

In this narrative review, studies were searched in electronic databases according to article titles, abstract contents, and relevance in the field of FMT through the end of April 2018. The databases used in this review included PubMed, MEDLINE, Google Scholar, and Cochrane Databases. The main terms applied were Clostridium difficile, Clostridium difficile infection, fecal microbiota transplantation, fecal transplantation, fecal bacteriotherapy, intestinal microbiota transplantation, floral reconstitution, infectious diarrhea, donor selection, related donor, fresh stool, frozen stool, capsules, colonoscopy, enema, and management. We also manually searched references to identify additional relevant studies. Articles published in languages other than English were excluded.

\section{Related versus unrelated donors}

Early FMT practices offered patients the opportunity to select relatives as a source of stool for transplantation [6,7]. In the event the patient could not identify a donor, a healthy volunteer was chosen. The selected volunteers were often other hospital patients, medical students, or residents [6-9]. Early reviews noted the preference for related donors [10-12] due to their genetic similarity and shared environment, both of which are known to influence gut diversity [13]. A shared environment also reduced the risk of transferring infectious agents to the patient $[10,14,15]$. However, it was noted that there was no rationale for excluding healthy volunteers [16], and subsequent systematic reviews [4,17] and meta-analysis [18] did not report a statistically significant difference in outcomes based on donor selection. Recently, with the use of stool banks, the use of unrelated donors has increased significantly $[19,20]$.

There are limited data on direct comparisons of related and unrelated donors. Inferences from randomized controlled trials (RCTs) are also limited, as those trials were not structured to investigate the donor-patient relationship and their outcomes (Table 1) [5,23-29]. Retrospective studies from the United States [21] and Finland [22] were limited by small sample sizes and found no significant difference in outcomes after eight weeks and one year, respectively (100\% vs. $78.6 \%$ resolution; $70 \%$ vs. $92 \%$ resolution, related and unrelated donors respectively). Six RCTs used exclusively unrelated or related donors, or a mixture $[5,23,24,26-28]$, while two RCTs used almost exclusively related donors [25,29]. The rate of resolution in 7 of 8 RCTs ranged from $87-96.2 \%$; one study that utilized a single enema infusion reported a resolution of $43.8 \%$. When compared to the resolution rate of other studies that utilized a single enema infusion, it did not appear to be an outlier (47.9\% [30] and 51.6\% [31]). Overall, current evidence indicates that the success of FMT does not depend on the donor-patient relationship; however, larger studies should be designed to explore this area in greater detail.

The advantages of using unrelated donors stem from their easy access and availability from stool banks. It can take weeks to screen a donor [4], thus time and capital are saved by treating patients with donations from an established source. Furthermore, accessibility to FMT is increased by removing the burden of donor screening and processing from healthcare providers $[21,32,33]$. However, ethical concerns regarding the privacy and ownership of stool have been raised [34,35]. It is unclear how these issues affect patients or stool banks.

Additional benefits of using unrelated donors include the avoidance of unpleasing or difficult conversations with related donors $[36,38,39]$. A survey of 183 FMT-naïve patients found that $28 \%$ of patients found selecting their own donor too unappealing to consider FMT as a treatment [37]. On the other hand, experience from another institution found that, when given a choice after switching to using frozen stool from unrelated donors, all patients preferred the unrelated donor option [21]. These data suggests that some patients struggle with discussing FMT with related donors and may prefer using unrelated donors.

A third option, the autologous donor, involves stool taken from an individual when their disease is in remission $[40,41]$. Stool can be used as treatment for that individual when the disease relapses. Although implementing this form of personalized medicine has been made easier by the creation of stool banks, its practicality and effectiveness have yet to be evaluated. Regardless of the donor utilized, the recommendation from consensus and working groups around the world emphasizes that every donor should be carefully and thoroughly screened before FMT is performed [42-46].

Table 1 Summary of randomized controlled trials of fecal microbiota transplantation for recurrent Clostridium difficile infection

\begin{tabular}{|c|c|c|c|c|c|c|}
\hline Publication & $\begin{array}{c}\text { \# of } \\
\text { patients }\end{array}$ & Donor & Preparation & Mode & $\begin{array}{l}\text { Overall resolution } \\
\text { rate }(\%)\end{array}$ & $\begin{array}{l}\text { Follow-up } \\
\text { duration }\end{array}$ \\
\hline Van Nood et al 2013 [23] & 16 & UR & Fresh & NDT & 94 & 10 weeks \\
\hline Youngster et al 2014 [24] & 20 & UR & Frozen & NGT, colonoscopy & 90 & 6 months \\
\hline Cammarota et al 2015 [25] & 20 & R \& UR & Fresh & Colonoscopy & 90 & 10 weeks or longer \\
\hline Kelly et al 2016 [26] & 22 & R \& UR & Fresh & Colonoscopy & 90.9 & 6 months \\
\hline Lee et al 2016 [5] & 178 & $\mathrm{R} \& \mathrm{UR}$ & Fresh, frozen & Enema & 96.1 & 13 weeks - 1 year \\
\hline Hota et al 2017 [29] & 16 & R \& UR & Fresh & Enema & 43.8 & 4 months \\
\hline Kao et al 2017 [27] & 105 & UR & Frozen & Colonoscopy, capsule & 96.2 & 3 months or longer \\
\hline Jiang et al 2017 [28] & 72 & UR & Fresh, frozen, lyophilized & Colonoscopy & 87 & 5 months \\
\hline
\end{tabular}

UR, unrelated; $R$, related; NDT, nasoduodenal tube; NGT, nasogastric tube 


\section{Frozen versus fresh fecal preparation}

Another significant evolution in the practice of fecal transplantation has been the use of frozen fecal matter. The earliest records can be traced to a report in 1998 by a group in Norway [47,48]. Frozen cultures had been used 9 years previously by Tvede and Rask-Maden to treat 5 patients, but their transplant material was referred to as "synthetic stool" as it was a limited combination of cultured bacterial strains [49]. The overall efficacy of the studies performed in Norway ranged from $83-100 \%[17,47,48]$.

Since then, most studies involving frozen fecal matter have reported an overall CDI cure rate between 81$100 \%$ [5,21,22,24,28,31,50-54] (Table 2). Two retrospective analyses [21,22] and three RCTs [5,24,28] directly compared fresh and frozen stool. All five studies reported primary outcomes that did not differ between fresh and frozen stool. No significant differences were noted, despite the range in the storage time of frozen fecal matter ( 1 week to 6 months). One small case series involving 3 patients [55] and a pilot clinical trial involving 7 patients who received frozen stool [56] reported lower resolution rates $(67 \%$ and $71.4 \%$ respectively). Besides the significant limitation of small sample sizes, the case series involved patients suffering from severe CDI, one who refused a second transplant and ultimately passed away from fulminant disease [55]. The pilot trial treated patients suffering an initial episode of CDI, some of whom were concomitantly or recently on antibiotics for other indications, with a protocol that did not include a bowel lavage [56]. These differences may have contributed to a lower resolution rate. Regardless, current evidence appears to indicate similar efficacy among frozen and fresh fecal preparations.

A central question related to the use of frozen stool is the viability of the microbiome over time. Costello et al tested bacterial viability after six months of storage [52]. The study showed that the microbiome remained largely unchanged after six months. CDI resolution has been achieved following 10 months of storage, while other studies have reported successful outcomes of FMT after six months $[28,50]$ and up

Table 2 Summary of studies of fecal microbiota transplant utilizing frozen stool

\begin{tabular}{|c|c|c|c|c|c|c|}
\hline Publication & $\begin{array}{c}\text { \# of } \\
\text { patients }\end{array}$ & Mode & $\begin{array}{c}\text { Stool } \\
\text { amount }(\mathrm{g})\end{array}$ & $\begin{array}{l}\text { Duration of } \\
\text { storage }\end{array}$ & $\begin{array}{l}\text { Overall resolution } \\
\text { rate }(\%)\end{array}$ & Follow-up period \\
\hline Gustafsson et al 1999a [48] & 14 & Enema & $5-10$ & $<2$ weeks & 100 & $2-3$ weeks up to 18 months \\
\hline Hamilton et al $2012^{\mathrm{b}}[21]$ & 21 & $\begin{array}{l}\text { Colonoscopy, colostomy, } \\
\text { push enteroscopy }\end{array}$ & 50 & $1-8$ weeks & $90.5-100$ & 3-12 months \\
\hline Weingarden et al 2013c [55] & 3 & Colonoscopy & 50 & Not reported & 67 & 6 weeks - 1 year \\
\hline Youngster et al 2014 [24] & 20 & NGT, colonoscopy & 41 & 29-156 days & 90 & 6 months \\
\hline Satokari et al 2015 [22] & 23 & Colonoscopy & 30 & Up to 16 weeks & 96 & 12 weeks - 1 year \\
\hline Youngster et al 2014 [90] & 20 & Capsule & 48 & 30-252 days & 90 & 6 months \\
\hline Orenstein et al 2016 [31] & 31 & Enema & 50 & Not reported & 87.1 & 6 months \\
\hline Hirsch et al 2015 [51] & 19 & Capsule & 2.3 & 49-63 days & 89 & 90 days \\
\hline Costello et al 2015 [52] & 20 & $\begin{array}{l}\text { Colonoscopy, push } \\
\text { enteroscopy }\end{array}$ & 30 & 227 days (170-272) & 100 & 3-14 months \\
\hline Youngster et al 2016 [50] & 180 & Capsule & 48 & Up to 6 months & 93 & Up to 6 months \\
\hline Lee et al $2016^{\mathrm{f}}[5]$ & 91 & Enema & 100 & Up to 30 days & 95.6 & 13 weeks - 1 year \\
\hline Camacho-Ortiz et al 2017 [56] & 7 & EGD, colonoscopy, PEG & 881.62 & Not reported & 71.4 & 30 days \\
\hline Lahtinen et al 2017 [53] & 13 & $\begin{array}{l}\text { Colonoscopy, } \\
\text { gastroscopy }\end{array}$ & 30 & Up to 16 weeks & 84.6 & 1 month \\
\hline Staley et al $2017^{\mathrm{g}}[54]$ & 49 & Capsule & 50 & Up to 1 year & 87.8 & Up to 12 months \\
\hline Kao et al 2017 [27] & 105 & Colonoscopy, capsule & $80-100$ & Up to 2 months & 96.2 & At least 3 months \\
\hline Jiang et al $2017^{\mathrm{h}}[28]$ & 72 & Colonoscopy & $\geq 50$ & Up to 6 months & 80.8 & 5 months \\
\hline
\end{tabular}

All studies utilized frozen, homologous stool from unrelated donors unless otherwise specified

${ }^{a}$ At least one patient had a second enema

bStudy also had related donors (10) and utilized fresh stool (22 cases); data shown for patients treated with frozen stool only

${ }^{c}$ Fresh stool used for 1 patient; data shown for patients treated with frozen stool only; all patients had severe CDI

${ }^{\mathrm{d}}$ An additional 26 patients received fresh stool (total of 49 patients); data only shown for patients who received frozen stool

EQR range in brackets

fSome patients received stool from a related donor (number unknown); only data for frozen patients shown

${ }^{\mathrm{g}}$ Lyophilized (Freeze-dried) stool used

hFresh, frozen and lyophilized stool used (25:24:23 patients); data shown for frozen and lyophilized patients only

EGD, esophagogastroduodenoscopy; NGT, nasogastric tube; PEG, percutaneous endoscopic gastrostomy 
to 1 year of storage [54]. Similar results have been reported in mice models, though a decline in quantity and diversity was observed after seven months of storage [57]. Given the benefits of frozen fecal transplant material and evidence to support its durability, clinicians trained in the use of FMT may be more inclined to use frozen preparations.

In 2015, an innovation in fecal preparation involved the use of freeze-dried stool [59]. Also known as lyophilized stool, a fresh suspension is transferred to a vacuum drier that produces a powdered product, which is then encapsulated. The motivation behind the creation of lyophilized stool was to develop a more concentrated and conveniently stored product with the hope that patients could utilize it at home. Various studies, including a case report [59], a retrospective study [60], pragmatic cohort study [54] and an RCT [28], have reported on the use of lyophilized stool with resolution rates ranging from $78-100 \%$. The RCT by Jiang et al found lyophilized stool to be statistically less effective than fresh stool (78\% vs. $100 \%$, $\mathrm{P}=0.022)$ but equally effective as frozen stool ( $78 \%$ vs. $83 \%$, $\mathrm{P}=0.255)$ in resolving recurrent CDI [28]. Further studies are needed to determine the efficacy and safety of lyophilized stool.

\section{Delivery methods}

Until 1990, enema was the method of choice for fecal transplant. Since then, various routes have been tested; however, the most optimal route of administration remains unclear. Delivery can be broadly classified into upper and lower gastrointestinal routes. Common upper gastrointestinal routes include esophagogastroduodenoscopy via enteric tubes (nasogastric, nasoduodenal, and nasojejunal tubes), and oral capsules [32,52,61-64]. Common lower gastrointestinal methods include colonoscopy and enemas [21,65-67]. There are benefits and pitfalls for each modality and physicians often choose one that best fits a combination of their patients' needs, their expertise and availability (Table 3 ).

The major advantage that colonoscopy offers over other modalities is the ability to visualize the entire colon [40,68-72]. It also enables reliable delivery of stool to affected segments of the bowel $[71,73,74]$ and possibly better retention of stool [73]. This can be particularly important, since it has been observed that the proximal colon has more severe pseudomembranous changes [75]. Furthermore, colonoscopy can deliver larger amounts of stool per transplant procedure $[40,71,74,76]$, associated with higher success rates [17]. Bowel preparation before the procedure is suggested to increase the likelihood of resolution of CDI by decreasing the number of spores and residual organisms [74]. However, there is a risk of bowel perforation, and those who are severely ill may not tolerate the procedure or anesthesia $[69,77,78,79]$.

Enemas are less invasive, easier to perform, and relatively less expensive [80]. The ease and simplicity of an enema allows it to be used in the hospital, ambulatory offices, and even at home $[81,82]$. However, there are greater concerns regarding retention of stool, as well as the risk that stool would not reach beyond the splenic flexure [72], which may require multiple infusions to achieve efficacy [83]. Greater facility time and personnel are sometimes required to maintain and rotate the patient between various positions to compensate for poor retention [70]. Additionally, patients with poor sphincter tone or issues with incontinence may augment concerns about retention [80].

Upper gastrointestinal routes are typically faster, less expensive and better tolerated compared to colonoscopy, though not as esthetically pleasing to some patients $[12,15,16,61,68,70]$. Typically, less stool sample is used when upper gastrointestinal

Table 3 Summary of studies of fecal microbiota transplantation delivered via oral capsules

\begin{tabular}{|c|c|c|c|c|c|c|c|}
\hline Publication & $\begin{array}{c}\text { \# of } \\
\text { patients }\end{array}$ & $\begin{array}{l}\text { Amount of } \\
\text { stool (g) }\end{array}$ & $\begin{array}{l}\text { Capsule } \\
\text { preparation }\end{array}$ & $\begin{array}{l}\text { Duration of } \\
\text { storage (days) }\end{array}$ & $\begin{array}{l}\text { Capsules/ } \\
\text { treatment }\end{array}$ & $\begin{array}{l}\text { Overall cure } \\
\text { rate } \%\end{array}$ & $\begin{array}{l}\text { Duration of } \\
\text { follow-up }\end{array}$ \\
\hline Louie et al 2013 [88] & 27 & approx. 100 & Fresh & Within hours & $24-34$ & 100 & 6 months \\
\hline Youngster et al 2014 [90] & 20 & 48 & Frozen & $30-252$ & 30 & 90 & 6 months \\
\hline Tian et al 2015 [59] & 1 & 50 & Lyophilized & Not reported & 10 & 100 & $>14$ days \\
\hline Hirsch et al 2015 [51] & 19 & 2.3 & Frozen & $49-63$ & $6-22$ & 89 & 90 days \\
\hline Hecker et al 2016 ${ }^{\mathrm{b}}[60]$ & 20 & 40 & Lyophilized & Not reported & $20-40$ & 95 & 204 days (31-408) \\
\hline Youngster et al 2016 [50] & 180 & 48 & Frozen & Up to 180 & 30 & 93 & Up to 6 months \\
\hline Staley et al $2017^{\complement}$ [54] & 49 & 50 & Lyophilized & Up to 365 & $2-27$ & 87.8 & Up to 12 months \\
\hline Kao et al 2017d [27] & 53 & $80-100$ & Frozen & Up to 60 & 40 & 96.2 & At least 3 months \\
\hline
\end{tabular}

All studies used homologous stool from unrelated donors

A multicenter retrospective publication by Hagel et al includes 13 patients treated by capsule FMT, but not enough information is provided to include in the chart

${ }^{a}$ Follow up unknown

${ }^{\mathrm{b}}$ Average number of days followed-up, range in brackets

'The protocol evolved over time, partly because of limited resources: 6 patients received 24-27 capsules/treatment (taken over 2-3 days), 14 patients received 14 capsules/treatment (taken within one day), and 30 received 2-3 capsules/treatment (taken in one single ingestion)

dTotal number of patients in the study was 105; 52 patients received fecal microbiota transplantation via colonoscopy. Cure rate shown is only for participants who received capsules 
routes are used, possibly to avoid regurgitation as well as better retention rates $[61,84]$. On the other hand, this has also been suggested as a reason why some transplants fail [17]. Common concerns include degradation by the gastric milieu, aspiration, hemorrhage and perforation of the upper gastrointestinal system $[68,85-87]$. This was supported by Wang et al who demonstrated in a systematic review that the rate of adverse events was more common when upper compared to lower gastrointestinal routes were used (43.6\% vs. $17.7 \%)$ [58].

The most recently developed mode of stool delivery is in the form of oral capsules $[88,89]$. It involves the delivery of stool mixed with a cryoprotectant, most commonly glycerol, and double- or triple-encapsulated to protect the stool from stomach acidity. Capsules are minimally invasive, convenient, and eliminate the risk of perforation by endoscopic procedures. Additionally, capsules are more esthetically pleasing, as patients have shown a preference for this mode of delivery over others [27,37].

Studies comparing the different routes of FMT have had mixed results, most likely due to sample size and research design [92]. Postigo et al compared the efficacy of upper and lower routes of delivery. Using a pooled analysis of 182 patients, the study did not show a significant difference between lower gastrointestinal and upper gastrointestinal delivery of FMT 95\% (95\% confidence interval [CI] 92-97\%) vs. 88\% (95\%CI 82-94\%), respectively ( $\mathrm{P}=0.162$ ) [93]. An observational followup study by Gundacker et al found that FMT by nasogastric tube (NGT) was less effective than colonoscopy [65]. Subgroup analysis revealed that NGT was equally effective for patients who were severely ill (Charleston comorbidity index [CCI $]>5$ ) or moderately ill $(\mathrm{CCI}<5)$, although there was a trend towards increasing effectiveness with colonoscopy for severely ill patients. However, a small randomized study of 20 patients by Youngster et al found colonoscopy and NGT to be equally successful [24]. A larger study by Kao et al involving 116 patients (57 patients randomized to the capsule group and 59 to the colonoscopy group) found that the use of capsules was non-inferior to colonoscopy [27]. The study showed that $96.2 \%$ of patients achieved prevention of recurrent CDI after a single treatment in both groups (capsule $=51 / 53$, colonoscopy $=50 / 52$; difference $0 \%$; 1 -sided $95 \%$ CI $-6.1 \%$ to infinity; $\mathrm{P}<0.001$ ). Evidence from these comparisons largely indicates that upper gastrointestinal methods of delivery can be equally effective as lower gastrointestinal methods. Furthermore, the high efficacy of FMT capsules, combined with their convenience, safety and esthetics, make them an attractive option for many patients.

\section{Cost-effectiveness of FMT}

CDI places a large burden on the healthcare system and makes it imperative to develop guidelines that emphasize costeffective therapies [93-97]. A meta-analysis estimated the total financial burden of inpatient management of CDI in the United States to be $\$ 6.3$ billion in 2015 [94]. In Europe, the economic burden of CDI was estimated to be roughly $€ 3$ billion [98], with costs per episode ranging between $€ 5798$ and $€ 11,202$ [97]. Given the effectiveness of FMT in the management of recurrent CDI, several studies have evaluated its cost-effectiveness [99-104].

The first cost-effective analysis compared three types of FMT (colonoscopy, duodenal infusion, and enema) and standard antibiotic therapy in the US. The analysis began with the first episode of recurrence and utilized contemporary guidelines to model two additional episodes of recurrence. At a willingness-to-pay threshold of $\$ 50,000$ /quality-adjusted life year (QALY), they found that FMT via colonoscopy was cost-effective compared to vancomycin and dominant (both cheaper and more effective) compared to the other therapies [99]. Of the several assumptions that went into the model, the choice to model FMT with only a single infusion of stool per treatment should be noted. If multiple infusions were permitted, the resolution rates for FMT via enema or duodenal infusion might have been higher ( 0.813 vs. 0.926 and 0.815 vs. 0.94 , respectively), which may have significantly altered the conclusions of the study.

Two other cost-effectiveness analyses have led to mixed conclusions. A decision-analytic model involving Markov processes compared colonoscopy, enema, NGT and standard antibiotic therapy, beginning with the first recurrence of CDI. The analysis, from the perspective of the ministry of health in Ontario, Canada, concluded that FMT via colonoscopy dominated all other strategies. Sensitivity analysis revealed it to be dominant in $87 \%$ of simulations. FMT via enema was preferred if colonoscopy was not available [100]. Another decision-analytic model, from France, compared various methods of FMT (colonoscopy, duodenal infusion, enema), vancomycin and fidaxomicin, for the second recurrence of CDI. Using the WHO's commission on macroeconomics and health to set the willingness-to-pay threshold at $\$ 32,000$, they found FMT via enema to be highly cost-effective (incremental cost-effectiveness ratio [ICER] \$18,092/QALY) compared to vancomycin. Although FMT via colonoscopy was still costeffective according to WHO guidelines, it was not as costeffective as FMT via enema (ICER \$73,653/QALY) [101].

Other cost-effectiveness studies for recurrent CDI have limited their scope to comparing specific methods. One study compared FMT via colonoscopy to vancomycin for the third recurrence of CDI. They found that FMT dominated vancomycin unless the cure rate with vancomycin was greater than $90 \%$ or the costs of FMT exceeded \$3,205 (2011 USD) [102]. Another study used Markov's model to compare two methods of FMT (nasoduodenal infusion and colonoscopy) and vancomycin for the first recurrence of CDI. From the perspective of the healthcare system in Australia, the study found both methods of FMT to be dominant over vancomycin, with an estimated savings of over AU\$1.37 million (2015 Australian dollars) per year. While no significant differences were reported between the various methods of FMT, the study did not incorporate the risks associated with nasoduodenal infusion into their model [103].

Additionally, a decision-analytic model by Varier et al compared FMT via colonoscopy to metronidazole and vancomycin, from the perspective of a third-party payer. Given the lack of published data on the effectiveness of FMT for initial CDI, the authors assumed that the procedure was as 
effective as it was for recurrent CDI [104]. At a willingness-topay threshold of $\$ 100,000$ (2011 US dollars), the base case of FMT was not cost-effective when compared to metronidazole (ICER \$124,964/QALY) but was dominant over vancomycin. FMT would have dominated metronidazole if the cost of the procedure was less than $\$ 584$, the cost of metronidazole was over $\$ 559$, or the cure rate with metronidazole was less than $71 \%$ [104]. Recently, a small RCT in Norway showed that, when FMT was used as primary therapy for CDI, overall response to treatment was achieved in $7(n=9)$ patients in the FMT group (78\%; 95\%CI 40-97), compared with $5(\mathrm{n}=11)$ in the metronidazole group $(45 \%$; $95 \% \mathrm{CI} 17-77)(\mathrm{P}=0.20)$ [105]. However, the study did not show statistical significance. Longitudinal studies are needed to define the role of FMT in the management of primary CDI. Currently, it appears that FMT may not be a cost-effective strategy for initial cases of CDI.

\section{Concluding remarks}

FMT is an effective and robust strategy for treating recurrent CDI. Our narrative review has shown that the success of FMT does not depend on the donor-patient relationship. To this end, the use of unrelated donor stool is becoming widely accepted with the creation of stool banks. However, further studies are needed to clarify storage requirements and the optimal freezing time before declining microbial function and diversity. Furthermore, several FMT techniques are used in the process of fecal transplantation. Based upon current data, we believe colonoscopy to be the most effective strategy. However, capsule FMT offers patients a more convenient and esthetically pleasing option. Cost-effectiveness models comparing these various approaches support the use of fecal transplant using colonoscopy over antibiotic therapy for treating recurrent CDI. However, there remains a knowledge gap regarding the costeffectiveness of capsule FMT.

\section{References}

1. Zimlichman E, Henderson D, Tamir O, et al. Health careassociated infections: a meta-analysis of costs and financial impact on the US health care system. JAMA Intern Med 2013;173:2039-2046.

2. Olsen MA, Yan Y, Reske KA, Zilberberg MD, Dubberke ER. Recurrent Clostridium difficile infection is associated with increased mortality. Clin Microbiol Infect 2015;21:164-170.

3. Cohen SH, Gerding DN, Johnson S, et al; Infectious Diseases Society of America. Clinical practice guidelines for Clostridium difficile infection in adults: 2010 update by the society for healthcare epidemiology of America (SHEA) and the infectious diseases society of America (IDSA). Infect Control Hosp Epidemiol 2010;31:431-455.

4. Kassam Z, Lee CH, Yuan Y, Hunt RH. Fecal microbiota transplantation for Clostridium difficile infection: systematic review and meta-analysis. Am J Gastroenterol 2013;108:500-508.

5. Lee $\mathrm{CH}$, Steiner T, Petrof EO, et al. Frozen vs fresh fecal microbiota transplantation and clinical resolution of diarrhea in patients with recurrent Clostridium difficile infection: a randomized clinical trial. JAMA 2016;315:142-149.

6. Kernsten HH. Intentional replacement of bacteria following antibiotic therapy. J Iowa State Med Soc 1958;48:240-243.

7. Eiseman B, Silen W, Bascom GS, Kauvar AJ. Fecal enema as an adjunct in the treatment of pseudomembranous enterocolitis. Surgery 1958;44:854-859.

8. Cutolo LC, Kleppel NH, Freund HR, Holker J. Fecal feedings as therapy in staphylococcus enterocolitis. NY State J Med 1959;59:3831-3833.

9. Bowden TA Jr, Mansberger AR Jr, Lykins LE. Pseudomembraneous enterocolitis: mechanism for restoring floral homeostasis. Am Surg 1981;47:178-183.

10. Borody TJ. "Flora Power" - fecal bacteria cure chronic C. difficile diarrhea. Am J Gastroenterol 2000;95:3028-3029.

11. Borody TJ, Warren EF, Leis SM, Surace R, Ashman O, Siarakas S. Bacteriotherapy using fecal flora: toying with human motions. J Clin Gastroenterol 2004;38:475-483.

12. Bakken JS. Fecal bacteriotherapy for recurrent Clostridium difficile infection. Anaerobe 2009;15:285-289.

13. Tasnim N, Abulizi N, Pither J, Hart MM, Gibson DL. Linking the gut microbial ecosystem with the environment: does gut health depend on where we live? Front Microbiol 2017;8:1935.

14. Aas J, Gessert CE, Bakken JS. Recurrent Clostridium difficile colitis: case series involving 18 patients treated with donor stool administered via a nasogastric tube. Clin Infect Dis 2003;36:580-585.

15. Garborg K, Waagsbø B, Stallemo A, Matre J, Sundøy A. Results of faecal donor instillation therapy for recurrent Clostridium difficile-associated diarrhoea. Scand I Infect Dis 2010;42:857-861.

16. van Nood E, Speelman P, Kuijper EJ, Keller JJ. Struggling with recurrent Clostridium difficile infections: is donor faeces the solution? Euro Surveill 2009;14:pii:19316.

17. Gough E, Shaikh H, Manges AR. Systematic review of intestinal microbiota transplantation (fecal bacteriotherapy) for recurrent Clostridium difficile infection. Clin Infect Dis 2011;53:994-1002.

18. Li YT, Cai HF, Wang ZH, Xu J, Fang JY. Systematic review with meta-analysis: long-term outcomes of faecal microbiota transplantation for Clostridium difficile infection. Aliment Pharmacol Ther 2016;43:445-457.

19. Shin JH, Chaves-Olarte E, Warren CA. Clostridium difficile infection. Microbiol Spectr 2016;4. doi: 10.1128/microbiolspec. EI10-0007-2015

20. Terveer EM, van Beurden YH, Goorhuis A, et al. How to: Establish and run a stool bank. Clin Microbiol Infect 2017;23:924-930.

21. Hamilton MJ, Weingarden AR, Sadowsky MJ, Khoruts A. Standardized frozen preparation for transplantation of fecal microbiota for recurrent Clostridium difficile infection. Am J Gastroenterol 2012;107:761-767.

22. Satokari R, Mattila E, Kainulainen V, Arkkila PE. Simple faecal preparation and efficacy of frozen inoculum in faecal microbiota transplantation for recurrent Clostridium difficile infectionan observational cohort study. Aliment Pharmacol Ther 2015;41:46-53.

23. van Nood E, Vrieze A, Nieuwdorp M, et al. Duodenal infusion of donor feces for recurrent Clostridium difficile. $N$ Engl J Med 2013;368:407-415.

24. Youngster I, Sauk J, Pindar C, et al. Fecal microbiota transplant for relapsing Clostridium difficile infection using a frozen inoculum from unrelated donors: a randomized, open-label, controlled pilot study. Clin Infect Dis 2014;58:1515-1522.

25. Cammarota G, Masucci L, Ianiro G, et al. Randomised clinical trial: faecal microbiota transplantation by colonoscopy vs. vancomycin for the treatment of recurrent Clostridium difficile infection. Aliment Pharmacol Ther 2015;41:835-843.

26. Kelly CR, Khoruts A, Staley C, et al. Effect of fecal microbiota 
transplantation on recurrence in multiply recurrent Clostridium difficile infection: a randomized trial. Ann Intern Med 2016;165:609-616.

27. Kao D, Roach B, Silva M, et al. Effect of oral capsule- vs colonoscopy-delivered fecal microbiota transplantation on recurrent Clostridium difficile infection: a randomized clinical trial. JAMA 2017;318:1985-1993.

28. Jiang ZD, Ajami NJ, Petrosino JF, et al. Randomised clinical trial: faecal microbiota transplantation for recurrent Clostridium difficile infection fresh, or frozen, or lyophilised microbiota from a small pool of healthy donors delivered by colonoscopy. Aliment Pharmacol Ther 2017;45:899-908.

29. Hota SS, Sales V, Tomlinson G, et al. Oral vancomycin followed by fecal transplantation versus tapering oral vancomycin treatment for recurrent Clostridium difficile infection: an open-label, randomized controlled trial. Clin Infect Dis 2017;64:265-271.

30. Lee CH, Belanger JE, Kassam Z, et al. The outcome and longterm follow-up of 94 patients with recurrent and refractory Clostridium difficile infection using single to multiple fecal microbiota transplantation via retention enema. Eur J Clin Microbiol Infect Dis 2014;33:1425-1428.

31. Orenstein R, Dubberke E, Hardi R, et al; PUNCH CD Investigators. Safety and durability of RBX2660 (microbiota suspension) for recurrent Clostridium difficile infection: results of the PUNCH CD Study. Clin Infect Dis 2016;62:596-602.

32. Rubin TA, Gessert CE, Aas J, Bakken JS. Fecal microbiome transplantation for recurrent Clostridium difficile infection: report on a case series. Anaerobe 2013;19:22-26.

33. Kelly CP. Fecal microbiota transplantation-an old therapy comes of age. N Engl J Med 2013;368:474-475.

34. Daloiso V, Minacori R, Refolo P, et al. Ethical aspects of fecal microbiota transplantation (FMT). Eur Rev Med Pharmacol Sci 2015; 19:3173-3180.

35. Hawkins AK, O’Doherty KC. "Who owns your poop?": insights regarding the intersection of human microbiome research and the ELSI aspects of biobanking and related studies. BMC Med Genomics 2011;4:72.

36. Zellmer C, De Wolfe TJ, Van Hoof S, Blakney R, Safdar N. Patient perspectives on fecal microbiota transplantation for Clostridium difficile infection. Infect Dis Ther 2016;5:155-164.

37. Zipursky JS, Sidorsky TI, Freedman CA, Sidorsky MN, Kirkland KB. Patient attitudes toward the use of fecal microbiota transplantation in the treatment of recurrent Clostridium difficile infection. Clin Infect Dis 2012;55:1652-1658.

38. Park L, Mone A, Price JC, et al. Perceptions of fecal microbiota transplantation for Clostridium difficile infection: factors that predict acceptance. Ann Gastroenterol 2017;30:83-88.

39. Pakyz AL, Moczygemba LR, VanderWielen LM, Edmond MB. Fecal microbiota transplantation for recurrent Clostridium difficile infection: The patient experience. Am J Infect Control 2016;44:554-559.

40. Duplessis CA, You D, Johnson M, Speziale A. Efficacious outcome employing fecal bacteriotherapy in severe Crohn's colitis complicated by refractory Clostridium difficile infection. Infection 2012;40:469-472.

41. Wang ZK, Yang YS, Chen Y, Yuan J, Sun G, Peng LH. Intestinal microbiota pathogenesis and fecal microbiota transplantation for inflammatory bowel disease. World $J$ Gastroenterol 2014;20:14805-14820.

42. Cammarota G, Ianiro G, Tilg $\mathrm{H}$, et al; European FMT Working Group. European consensus conference on faecal microbiota transplantation in clinical practice. Gut 2017;66:569-580.

43. Moayyedi P, Marshall JK, Yuan Y, Hunt R. Canadian Association of Gastroenterology position statement: fecal microbiota transplant therapy. Can J Gastroenterol Hepatol 2014;28:66-68.

44. Allen-Vercoe E, Reid G, Viner N, et al. A Canadian Working
Group report on fecal microbial therapy: microbial ecosystems therapeutics. Can J Gastroenterol 2012;26:457-462.

45. Kelly CR, Kahn S, Kashyap P, et al. Update on fecal microbiota transplantation 2015: indications, methodologies, mechanisms, and outlook. Gastroenterology 2015;149:223-237.

46. Position Statement On Faecal Microbiota Transplant (FMT). http://www.gesa.org.au/public/13/files/GESA $\% 20$ position $\% 20$ statement\%20FMT\%20FAM\%20JMA\%20SPC\%2020170426.pdf [Accessed on May 19, 2018].

47. Gustafsson A, Lund-Tønnesen S, Berstad A, Midtvedt T, Norin E. Faecal short-chain fatty acids in patients with antibioticassociated diarrhoea, before and after faecal enema treatment. Scand J Gastroenterol 1998;33:721-727.

48. Gustafsson A, Berstad A, Lund-Tønnesen S, Midtvedt T, Norin E. The effect of faecal enema on five microflora-associated characteristics in patients with antibiotic-associated diarrhoea. Scand J Gastroenterol 1999;34:580-586.

49. Tvede M, Rask-Madsen J. Bacteriotherapy for chronic relapsing Clostridium difficile diarrhoea in six patients. Lancet 1989;1:1156-1160.

50. Youngster I, Mahabamunuge J, Systrom HK, et al. Oral, frozen fecal microbiota transplant (FMT) capsules for recurrent Clostridium difficile infection. BMC Med 2016;14:134.

51. Hirsch BE, Saraiya N, Poeth K, Schwartz RM, Epstein ME, Honig G. Effectiveness of fecal-derived microbiota transfer using orally administered capsules for recurrent Clostridium difficile infection. BMC Infect Dis 2015;15:191.

52. Costello SP, Conlon MA, Vuaran MS, Roberts-Thomson IC, Andrews JM. Faecal microbiota transplant for recurrent Clostridium difficile infection using long-term frozen stool is effective: clinical efficacy and bacterial viability data. Aliment Pharmacol Ther 2015;42:1011-1018.

53. Lahtinen P, Mattila E, Anttila VJ, et al. Faecal microbiota transplantation in patients with Clostridium difficile and significant comorbidities as well as in patients with new indications: A case series. World J Gastroenterol 2017;23:7174-7184.

54. Staley C, Hamilton MJ, Vaughn BP, et al. Successful resolution of recurrent Clostridium difficile infection using freeze-dried, encapsulated fecal microbiota; pragmatic cohort study. Am J Gastroenterol 2017;112:940-947.

55. Weingarden AR, Hamilton MJ, Sadowsky MJ, Khoruts A. Resolution of severe Clostridium difficile infection following sequential fecal microbiota transplantation. Clin Gastroenterol 2013;47:735-737.

56. Camacho-Ortiz A, Gutiérrez-Delgado EM, Garcia-Mazcorro JF, et al. Randomized clinical trial to evaluate the effect of fecal microbiota transplant for initial Clostridium difficile infection in intestinal microbiome. PLoS One 2017;12:e0189768.

57. Jiang ZD, Alexander A, Ke S, et al. Stability and efficacy of frozen and lyophilized fecal microbiota transplant (FMT) product in a mouse model of Clostridium difficile infection (CDI). Anaerobe 2017;48:110-114.

58. Wang $\mathrm{S}, \mathrm{Xu} \mathrm{M}$, Wang $\mathrm{W}$, et al. Systematic review: adverse events of fecal microbiota transplantation. PLoS One 2016;11:e0161174.

59. Tian H, Ding C, Gong J, Wei Y, McFarland LV, Li N. Freezedried, capsulized fecal microbiota transplantation for relapsing Clostridium difficile infection. J Clin Gastroenterol 2015;49:537-538.

60. Hecker MT, Obrenovich ME, Cadnum JL, et al. Fecal microbiota transplantation by freeze-dried oral capsules for recurrent Clostridium difficile infection. Open Forum Infect Dis 2016;3:ofw091.

61. Gweon TG, Kim J, Lim CH, et al. Fecal microbiota transplantation using upper gastrointestinal tract for the treatment of refractory or severe complicated Clostridium difficile infection in elderly patients in poor medical condition: the first study in an Asian 
country. Gastroenterol Res Pract 2016;2016:2687605.

62. Bauer MP, van Dissel JT. Alternative strategies for Clostridium difficile infection. Int $J$ Antimicrob Agents 2009;33(Suppl 1):S51-S56.

63. Link A, Lachmund T, Schulz C, Weigt J, Malfertheiner P. Endoscopic peroral jejunal fecal microbiota transplantation. Dig Liver Dis 2016;48:1336-1339.

64. Trubiano JA, Gardiner B, Kwong JC, Ward P, Testro AG, Charles PG. Faecal microbiota transplantation for severe Clostridium difficile infection in the intensive care unit. Eur J Gastroenterol Hepatol 2013;25:255-257.

65. Gundacker ND, Tamhane A, Walker JB, Morrow CD, Rodriguez JM. Comparative effectiveness of faecal microbiota transplant by route of administration. $J$ Hosp Infect 2017;96:349-352.

66. Louie TJ, Louie MR, Krulicki W, Byrne B, Ward L. Home-based fecal flora infusion to arrest multiply-recurrent Clostridium difficile infection (CDI). In: Abstracts of the Interscience Conference on Antimicrobial Agents \& Chemotherapy (Washington DC). Arlington, Virginia: Infectious Disease Society of America, 2008.

67. Schneider KM, Wirtz TH, Kroy D, et al. Successful fecal microbiota transplantation in a patient with severe complicated Clostridium difficile infection after liver transplantation. Case Rep Gasroenterol 2018;12:76-84.

68. Mattila E, Uusitalo-Seppälä $R$, Wuorela $M$, et al. Fecal transplantation, through colonoscopy, is effective therapy for recurrent Clostridium difficile infection. Gastroenterology 2012;142:490-496.

69. Pathak R, Enuh HA, Patel A, Wickremesinghe P. Treatment of relapsing Clostridium difficile infection using fecal microbiota transplantation. Clin Exp Gastroenterol 2013;7:1-6.

70. Cammarota G, Ianiro G, Gasbarrini A. Fecal microbiota transplantation for the treatment of Clostridium difficile infection: a systematic review. J Clin Gastroenterol 2014;48:693-702.

71. Kelly CR, de Leon L, Jasutkar N. Fecal microbiota transplantation for relapsing Clostridium difficile infection in 26 patients: methodology and results. J Clin Gastroenterol 2012;46:145-149.

72. Persky SE, Brandt LJ. Treatment of recurrent Clostridium difficileassociated diarrhea by administration of donated stool directly through a colonoscope. Am J Gastroenterol 2000;95:3283-3285.

73. Rohlke F, Surawicz CM, Stollman N. Fecal flora reconstitution for recurrent Clostridium difficile infection: results and methodology. J Clin Gastroenterol 2010;44:567-570.

74. Yoon SS, Brandt LJ. Treatment of refractory/recurrent C. difficileassociated disease by donated stool transplanted via colonoscopy: a case series of 12 patients. J Clin Gastroenterol 2010;44:562-566.

75. Guo B, Harstall C, Louie T, Veldhuyzen van Zanten S, Dieleman LA. Systematic review: faecal transplantation for the treatment of Clostridium difficile-associated disease. Aliment Pharmacol Ther 2012;35:865-875.

76. Brandt LJ, Borody TJ, Campbell J. Endoscopic fecal microbiota transplantation: "first-line" treatment for severe Clostridium difficile infection? J Clin Gastroenterol 2011;45:655-657.

77. Ehlermann P, Dösch AO, Katus HA. Donor fecal transfer for recurrent Clostridium difficile-associated diarrhea in heart transplantation. J Heart Lung Transplant 2014;33:551-553.

78. Zainah H, Hassan M, Shiekh-Sroujieh L, Hassan S, Alangaden G, Ramesh M. Intestinal microbiota transplantation, a simple and effective treatment for severe and refractory Clostridium difficile infection. Dig Dis Sci 2015;60:181-185.

79. Kelly CR, Ihunnah C, Fischer $M$, et al. Fecal microbiota transplant for treatment of Clostridium difficile infection in immunocompromised patients. Am J Gastroenterol 2014;109:1065-1071.

80. Kassam Z, Hundal R, Marshall JK, Lee CH. Fecal transplant via retention enema for refractory or recurrent Clostridium difficile infection. Arch Intern Med 2012;172:191-193.

81. Silverman MS, Davis I, Pillai DR. Success of self-administered home fecal transplantation for chronic Clostridium difficile infection. Clin Gastroenterol Hepatol 2010;8:471-473.

82. Duke PS, Fardy J. Recurrent Clostridium difficile infection treated with home fecal transplantation: a case report. J Med Case Rep 2014;28:393.

83. Brandt LJ, Aroniadis OC, Mellow M, et al. Long-term follow-up of colonoscopic fecal microbiota transplant for recurrent Clostridium difficile infection. Am J Gastroenterol 2012;107:1079-1087.

84. Bang BW, Park JS, Kim HK, et al. Fecal microbiota transplantation for refractory and recurrent Clostridium difficile infection: a case series of nine patients. Korean J Gastroenterol 2017;69:226-231.

85. Dutta SK, Girotra M, Garg S, et al. Efficacy of combined jejunal and colonic fecal microbiota transplantation for recurrent Clostridium difficile infection. Clin Gastroenterol Hepatol 2014;12:1572-1576.

86. Baxter M, Ahmad T, Colville A, Sheridan R. Fatal aspiration pneumonia as a complication of fecal microbiota transplant. Clin Infect Dis 2015;61:136-137.

87. Hagel S, Fischer A, Ehlermann P, et al; German Clinical Microbiome Study Group (GCMSG). Fecal microbiota transplant in patients with recurrent Clostridium difficile infection. Dtsch Arztebl Int 2016;113:583-589.

88. Louie T, Cannon K, O'Grady H, et al. Fecal microbiome transplantation (FMT) via oral fecal microbial capsules for recurrent Clostridium difficile infection (rCDI). ID week. 2013;201389.

89. Rao K, Young VB, Malani PN. Capsules for fecal microbiota transplantation in recurrent Clostridium difficile infection: the new way forward or a tough pill to swallow? JAMA 2017;318:1979-1980.

90. Youngster I, Russell GH, Pindar C, Ziv-Baran T, Sauk J, Hohmann EL. Oral, capsulized, frozen fecal microbiota transplantation for relapsing Clostridium difficile infection. JAMA 2014;312:1772-1778.

91. Quraishi MN, Widlak M, Bhala N, et al. Systematic review with meta-analysis: the efficacy of faecal microbiota transplantation for the treatment of recurrent and refractory Clostridium difficile infection. Aliment Pharmacol Ther 2017;46:479-493.

92. Postigo R, Kim JH. Colonoscopic versus nasogastric fecal transplantation for the treatment of Clostridium difficile infection: a review and pooled analysis. Infection 2012;40:643-648.

93. Bauer MP, Notermans DW, van Benthem BH, et al; ECDIS Study Group. Clostridium difficile infection in Europe: a hospital-based survey. Lancet 2011;377:63-73.

94. Zhang S, Palazuelos-Munoz S, Balsells EM, Nair H, Chit A, Kyaw MH. Cost of hospital management of Clostridium difficile infection in United States-a meta-analysis and modelling study. BMC Infect Dis 2016;16:447.

95. Borren NZ, Ghadermarzi S, Hutfless S, Ananthakrishnan AN. The emergence of Clostridium difficile infection in Asia: A systematic review and meta-analysis of incidence and impact. PLoS One 2017;12:e176797.

96. Roldan GA, Cui AX, Pollock NR. Assessing the burden of Clostridium difficile infection in low- and middle-income countries. J Clin Microbiol 2018;56: pii: e01747-pii: e01817

97. Reigadas Ramírez E, Bouza E.S. Economic burden of Clostridium difficile infection in European countries. In: Mastrantonio P., Rupnik M. (editors) Updates on Clostridium difficile in Europe. Advances in Experimental Medicine and Biology, vol 1050. Springer, Cham; 2018, pp. 1-12.

98. Jones AM, Kuijper EJ, Wilcox MH. Clostridium difficile: a European perspective. J Infect 2013;66:115-128. 
99. Konijeti GG, Sauk J, Shrime MG, Gupta M, Ananthakrishnan AN. Cost-effectiveness of competing strategies for management of recurrent Clostridium difficile infection: a decision analysis. Clin Infect Dis 2014;58:1507-1514.

100. Lapointe-Shaw L, Tran KL, Coyte PC, et al. Cost-effectiveness analysis of six strategies to treat recurrent Clostridium difficile infection. PLoS One 2016;11:e149521.

101. Baro E, Galperine T, Denies F, et al. Cost-effectiveness analysis of five competing strategies for the management of multiple recurrent community-onset Clostridium difficile infection in France. PLoS One 2017;12:e0170258.

102. Varier RU, Biltaji E, Smith KJ, et al. Cost-effectiveness analysis of fecal microbiota transplantation for recurrent Clostridium difficile infection. Infect Control Hosp Epidemiol 2015;36:438-444.

103. Merlo G, Graves N, Brain D, Connelly LB. Economic evaluation of fecal microbiota transplantation for the treatment of recurrent Clostridium difficile infection in Australia. J Gastroenterol Hepatol 2016;31:1927-1932.

104. Varier RU, Biltaji E, Smith KJ, et al. Cost-effectiveness analysis of treatment strategies for initial Clostridium difficile infection. Clin Microbiol Infect 2014;20:1343-1351.

105. Juul FE, Garborg K, Bretthauer M, et al. Fecal microbiota transplantation for primary Clostridium difficile infection. N Engl J Med 2018;378:2535-2536. 